\title{
Correlation of mortality with lesion level in patients with myelomeningocele: a population-based study
}

\author{
Joel Haakon Borgstedt-Bakke, ${ }^{1}$ Morten Fenger-Grøn, MSc, ${ }^{2}$ and \\ Mikkel Mylius Rasmussen, MD, $\mathrm{PhD}^{1}$
}

${ }^{1}$ Center for Experimental Neuroscience-Spine, Department of Neurosurgery, Aarhus University Hospital; and ${ }^{2}$ Research Unit for General Practice, Department of Public Health, Aarhus University, Aarhus, Denmark

\begin{abstract}
OBJECTIVE The aim of this study was to assess myelomeningocele mortality, correlate these findings to lesion level, and investigate mortality evolution.

METHODS From the population-based western Denmark myelomeningocele database, the authors extracted the records of 187 patients born between January 1, 1970, and July 1, 2015. Patients were categorized according to their most rostral lesion level into cervical, thoracic, lumbar, or sacral groups. Furthermore, patients were categorized based on their birth dates (1970-1979, 1980-1989, and 1990-2015). Mortality data was extrapolated from the university hospital's electronic charts, which are based on the Danish Civil Registration System, and compared according to mortality, lesion level, and date of birth. Data were also extracted from nationwide Danish registers. Additionally, the authors divided the patients according to date of birth before or after the advent of prenatal detection (2004), and compared mortality rates of these two groups.
\end{abstract}

RESULTS A thoracic lesion level was associated with a significantly higher mortality rate $(p=0.01)$. Two patients had a cervical lesion and were alive at the end of follow-up. The mortality rate decreased over time, although not significantly for the subsequent time periods. Prenatal detection did not affect mortality.

CONCLUSIONS The presented data suggest increased mortality with ascending lesion level in patients with myelomeningocele, except for patients with cervical lesions. The mortality rate improved over time, suggesting that modern treatment modalities improve survival in patients with myelomeningocele.

https://thejns.org/doi/abs/10.3171/2016.8.PEDS1654

KEY WORDS myelomeningocele; spina bifida; mortality; age group; sex; spine; congenital

$\mathrm{M}$ YELOMENINGOCELE is one of the most complex congenital malformations of the nervous system. Patients with myelomeningocele may suffer from hydrocephalus, epilepsy, neurogenic bladder and bowel dysfunction, muscle contractures leading to joint dislocations, tethered cord, and spinal deformity. $2,12,14,17,18$ Furthermore, these patients have the lowest health-related quality of life compared to patients with other spinal dysraphisms. ${ }^{15,19}$

Worldwide, the incidence of neural tube defects, of which myelomeningocele is the most common, ranges from 0.17 to 6.39 per 1000 live births. ${ }^{1}$ The incidence rate of myelomeningocele is decreasing, both worldwide ${ }^{1}$ and in
Denmark. ${ }^{3}$ In Denmark, the explanation for this decrease is most likely due to early termination after prenatal detection through high-quality ultrasonography. ${ }^{3}$ Folic acid fortification is the dominant preventative factor around the world..$^{10}$

Several decades ago, the mortality rate of patients with open spina bifida at birth was high and overall survival low compared with the general population. ${ }^{12}$ Although knowledge on mortality and cause of death in spina bifida exist in the literature, very sparse knowledge has been gathered from population-based sources. Consequently, the results from these sources could be biased due to patient selection. ${ }^{4,5,16}$ The aim of this study was to determine the mortality rate in a population-based myelomeningo- 
cele cohort, correlate these findings to lesion level, and investigate mortality evolution.

\section{Methods \\ Study Population}

We performed a population-based cohort study using follow-up data from nationwide Danish registers on all patients registered in the western Denmark myelomeningocele database. This database has collected information on all patients undergoing a surgical procedure or those hospitalized for myelomeningocele in the Department of Neurosurgery at Aarhus University Hospital, Denmark, since January 1, 1970. The treatment of myelomeningocele in western Denmark, which is a well-defined geographical area with approximately 2.0 million inhabitants (as of 1995; https://www.dst.dk/en), is exclusively performed at Aarhus University Hospital. All infants born with this malformation within western Denmark are therefore brought to the Department of Neurosurgery at Aarhus University Hospital and registered in the database. Among the data incorporated in the database are date of first myelomeningocele-related contact with the hospital and lesion level, as extracted from medical records by a specialist consultant. The patients were categorized into 1 of 4 categories according to their most rostral lesion level: cervical, thoracic, lumbar, and sacral. Prior to initiation of the study the Danish Health and Medicines Authority and the Danish Data Protection Agency gave permission to collect the required data.

By means of the unique personal identification number that has been assigned to all Danish citizens at birth or immigration since 1968 and contains essential information on sex and birth date, data from the western Denmark myelomeningocele database was linked on an individual level to vital status as registered in the Danish Civil Registration System (https://cpr.dk) as well as causes of death as registered in the Danish Register of Causes of Death. ${ }^{7}$

\section{Data Collection and Analysis}

We estimated hazard ratios (HRs) for the association between mortality and lesion level, year of birth, and sex, using Cox regression with age as the underlying timeline. Follow-up ended on the day of death or the end of the study period (November 9, 2015), whichever came first. The proportionality assumption was assessed graphically and by the introduction of an interaction term between time and the studied variables. The trend over time for mortality was estimated using time as a continuous variable and decade of birth as the scale unit. Because the cohort was well balanced with respect to the studied characteristics, we chose not to compromise power and validity of the statistical analyses by the introduction of mutual corrections.

Additionally, mortality was presented graphically by Kaplan-Meier survival curves. For presentation of the trend over time, patients were initially divided into 4 categories according to date of birth: 1970-1979, 1980-1989, 1990-1999, and 2000-2015. However, as the total risk time in the latter group was fairly small, a post hoc decision was made to collapse the 1990-1999 and 2000-2015 categories, as this provided an overview without obscur- ing important data points. For reference, we added curves depicting the general survival in the Danish population, estimated from publicly accessible data from Statistics Denmark (https://www.dst.dk/en). In a supplementary analysis, we studied mortality and lesion levels for the patients born after the advent of prenatal detection in Denmark (January 1, 2004). Stata statistical software (version 12 , StataCorp LP) was used to analyze the data. A p value $<0.05$ was considered statistically significant.

\section{Results}

\section{Patient Demographics}

The western Denmark myelomeningocele database comprised a total of 203 patients. Sixteen were excluded due to unknown mortality data $(\mathrm{n}=7)$ or incomplete clinical data $(n=9)$, which left a cohort of 187 participants.

Two participants (1\%) were born with a cervical lesion, $16(9 \%)$ with a thoracic lesion, $156(83 \%)$ with a lumbar lesion, and $13(7 \%)$ with a sacral lesion (Table 1). Fiftyeight patients (31\%) were born between January 1, 1970, and December 31, 1979: 1 (2\%) was born with a cervical lesion, $6(10 \%)$ with a thoracic lesion, $51(88 \%)$ with a lumbar lesion, and 0 with a sacral lesion.

Thirty-nine patients $(21 \%)$ were born between January 1, 1980, and December 31, 1989: 0 were born with a cervical lesion, 3 (8\%) with a thoracic lesion, $34(87 \%)$ with a lumbar lesion, and $2(5 \%)$ with a sacral lesion. Ninety patients (48\%) were born between January 1, 1990, and November 9, 2015: $1(1 \%)$ was born with a cervical lesion, 7 (8\%) with a thoracic lesion, 71 (79\%) with a lumbar lesion, and $11(12 \%)$ with a sacral lesion. Of the patients excluded from this study $(\mathrm{n}=16), 14$ were born between January 1, 1970, and December 31, 1979, and 2 between January 1, 1990, and November 9, 2015.

\section{Mortality of Entire Population}

Seven percent of all patients died in their first year of life, and $1 \%$ died between 1 and 5 years of age. The highest mortality rate of the population occurred in the first 3 months after birth, in which $30 \%$ of all deaths occurred, equal to $4 \%$ of the entire population. Pneumonia accounted for 4 deaths; meningitis, peritonitis, pyelonephritis, and sepsis for 2 deaths each; and epilepsy, malignant melanoma, respiratory failure, birth complication, and viral infection for 1 death each. The remaining patients $(n=$ 10) had unknown causes of death, accounting for $37 \%$ of all death occurrences. Sex was not a mortality-associated prognostic factor (HR 0.9, 95\% confidence interval [CI] $0.4-1.9)$ for males as compared with females $(\mathrm{p}=0.73)$.

\section{Lesion Level}

Survival was significantly correlated with lesion level (Fig. 1). As compared to patients with a lumbar lesion, who represented the vast majority of the cohort, patients with a thoracic lesion had a significantly poorer prognosis (HR 3.4, 95\% CI 1.4-8.5; $\mathrm{p}=0.01$ ), while for patients with a sacral lesion the observed mortality rate was slightly lower (HR 0.8), although sample sizes were too small to allow precise quantification in this matter. Both patients with a cervical lesion survived. 
TABLE 1. Patient demographics

\begin{tabular}{|c|c|c|c|c|}
\hline \multirow[b]{2}{*}{ Variable } & \multirow[b]{2}{*}{ Total } & \multicolumn{2}{|c|}{ Age (yrs) } & \multirow{2}{*}{$\begin{array}{c}\text { Males } \\
(\%)\end{array}$} \\
\hline & & Median & Range & \\
\hline \multicolumn{5}{|l|}{ Entire population } \\
\hline All patients & 187 & 24 & $0-46$ & $90(48)$ \\
\hline Patients alive & 160 & 25 & $0-46$ & $78(49)$ \\
\hline Patients deceased & 27 & 1 & $0-39$ & $12(44)$ \\
\hline \multicolumn{5}{|l|}{ Lesion level } \\
\hline \multicolumn{5}{|l|}{ Cervical } \\
\hline Total & 2 & 23 & $7-39$ & $1(50)$ \\
\hline Patients alive & 2 & 23 & $7-39$ & $1(50)$ \\
\hline Patients deceased & 0 & NA & NA & 0 \\
\hline \multicolumn{5}{|l|}{ Thoracic } \\
\hline Total & 16 & 24 & $0-44$ & $8(50)$ \\
\hline Patients alive & 10 & 29 & $10-44$ & $5(50)$ \\
\hline Patients deceased & 6 & 0 & $0-24$ & $3(50)$ \\
\hline \multicolumn{5}{|l|}{ Lumbar } \\
\hline Total & 156 & 24 & $0-46$ & $75(48)$ \\
\hline Patients alive & 136 & 26 & $9-46$ & $66(49)$ \\
\hline Patients deceased & 20 & 2 & $0-39$ & $9(45)$ \\
\hline \multicolumn{5}{|l|}{ Sacral } \\
\hline Total & 13 & 14 & $0-32$ & $6(46)$ \\
\hline Patients alive & 12 & 14 & $7-32$ & $6(50)$ \\
\hline Patients deceased & 1 & 0 & NA & 0 \\
\hline \multicolumn{5}{|l|}{ Time period } \\
\hline \multicolumn{5}{|l|}{ 1970-1979 } \\
\hline Total & 58 & 39 & $0-46$ & $25(43)$ \\
\hline Patients alive & 42 & 41 & $36-46$ & $17(40)$ \\
\hline Patients deceased & 16 & 1 & $0-39$ & $8(50)$ \\
\hline \multicolumn{5}{|l|}{ 1980-1989 } \\
\hline Total & 39 & 30 & $0-36$ & $22(56)$ \\
\hline Patients alive & 34 & 31 & $26-36$ & $20(59)$ \\
\hline Patients deceased & 5 & 2 & $0-26$ & $2(40)$ \\
\hline \multicolumn{5}{|l|}{ 1990-2015 } \\
\hline Total & 90 & 15 & $0-26$ & $43(48)$ \\
\hline Patients alive & 84 & 16 & $7-26$ & $41(49)$ \\
\hline Patients deceased & 6 & 1 & $0-14$ & $2(33)$ \\
\hline
\end{tabular}

$\mathrm{NA}=$ not applicable.

\section{Time Periods}

The patient mortality rate appeared to decrease over time (Fig. 2), and the Cox regression estimated a borderline significant time trend per time period (HR 0.7, 95\% CI $0.5-1.0 ; p=0.05)$, corresponding to a more than $80 \%$ reduction of mortality from the start to the end of the study period. Over this time span, a reduction of the mortality rate in the background population was observed as well, but on a far more modest level (Fig. 2).

\section{Consequences of Prenatal Detection Through High-Quality Ultrasonography}

From January 1, 2004, until the present, 2 of 23 patients with myelomeningocele died, resulting in a mortality rate

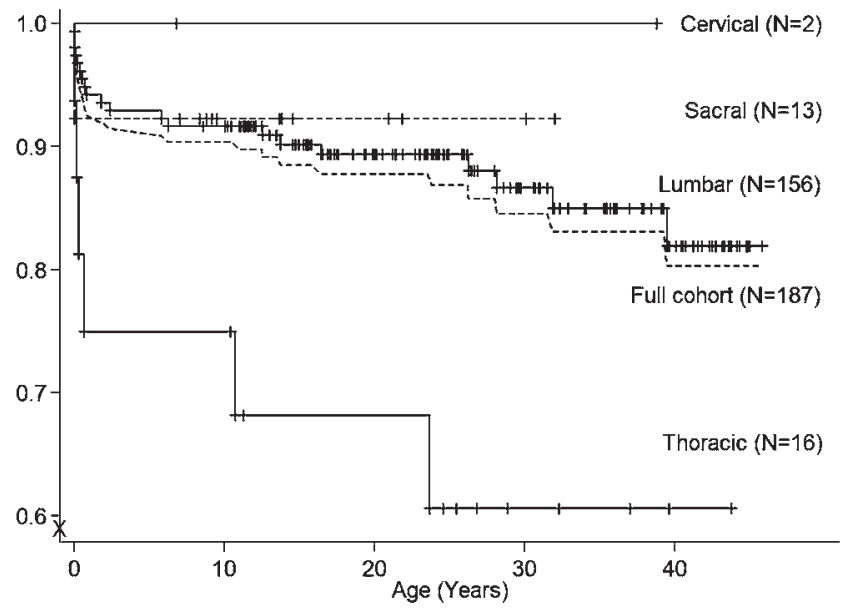

FIG. 1. Kaplan-Meier survival curve according to myelomeningocele level with censoring indicated by tick marks on the curves. Survival probability for the entire cohort is presented by the lower dashed line.

of $9 \%$, compared with $10 \%$ in the total patient cohort at a matching age level. The distribution of lesion level after the introduction of prenatal detection was 1 (4\%) with a cervical lesion, 4 (17\%) with a thoracic lesion, $13(57 \%)$ with a lumbar lesion, and $5(22 \%)$ with a sacral lesion. Due to the very low number of deaths $(n=2)$, a comparative statistical evaluation was not performed and descriptive data are presented instead.

\section{Discussion}

In this study, we observed that patients born with myelomeningocele have increased survival the later the year of birth. A major predictor for survival is level of the lesion, and death is predominant in infancy.

\section{Population-Based Data}

This study has 3 major advantages. The first advantage of this study is that it is population based. All patients undergoing surgery for myelomeningocele in western Denmark have been admitted to our neurosurgical department. In Denmark, socialized medicine is the dominant health care provided and encompasses all care for specialized conditions such as myelomeningocele. Therefore, it is safe to assume that all patients undergoing surgery for myelomeningocele in western Denmark since January 1, 1970, have been registered in our database. Second, the database only consists of patients born with myelomeningocele, producing data separate from other kinds of spina bifida. Third, when a patient dies, it is registered in our electronic chart through the Danish Civil Registration System, which makes our data reliable.

\section{Mortality}

Patients born with cervical myelomeningocele lesions have been reported to have better outcomes than those with more caudal lesions. ${ }^{6,8,13}$ In the literature, we found 29 cases reported with cervical lesions. None of these patients were reported as deceased. Furthermore, these reports noted that all patients achieved ambulation and 


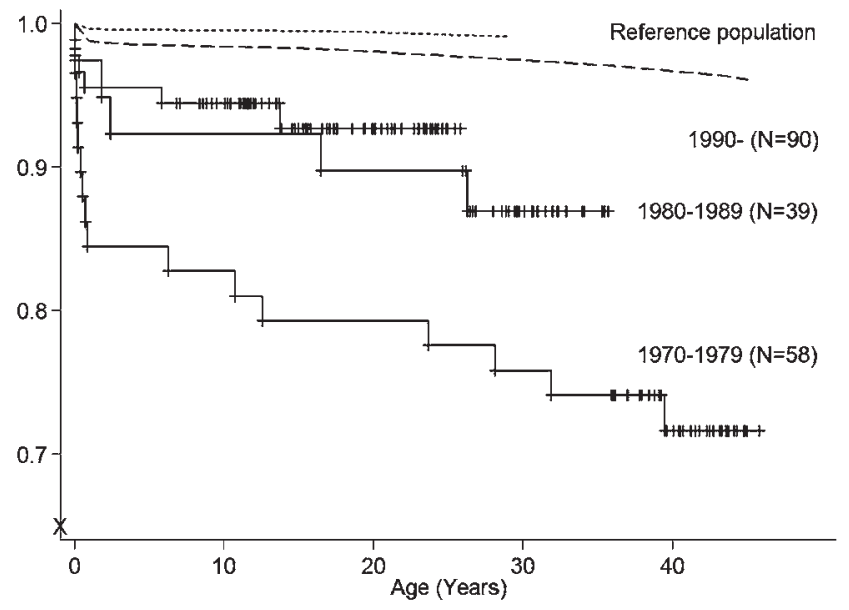

FIG. 2. Kaplan-Meier survival curve according to time of birth, with censoring indicated by tick marks on the curves. Survival probability in the full Danish population is presented as dashed and dotted lines at the top of the figure (beginning and end of the study period, respectively).

urinary continence. ${ }^{6,8}$ These findings are consistent with our findings, in which both patients with cervical lesions survived to the end of the study.

Disregarding the cervical group, the trend appears to be that ascending lesion level correlates with higher probability of death. One study found the same correlation between patient mortality and ascending sensory level. ${ }^{12}$ The same study reported a higher mortality rate than the one found in this study. This difference may be explained by differences in population composition, as the compared study population was born between 1963 and 1971. Furthermore, they found no difference in mortality rate between the sexes, consistent with our findings.

Our finding of decreased mortality through the decades is supported by a study reporting a higher mortality rate in patients born with myelomeningocele before the year of 1975. ${ }^{4}$ This suggests that modern treatment modalities have improved survival in patients born with myelomeningocele. Previous studies have found the highest mortality rates in the first 5 years of life. ${ }^{11,12,16}$ This is consistent with our population-based findings, even in the 21st century. The median age at death for the entire population was 1 year of age. The highest mortality rate was found in the first 3 months of life, accounting for $30 \%$ of all deceased patients.

The causes of death reported in this study do not form a coherent group. For the majority of patients who died, various infections appear to be the cause of death. However, $37 \%$ were unknown, which diminishes the value of an overall conclusion. This incoherence in the cause of death, and lack of complete data, appears to be the case for other studies $^{14,16}$ and may highlight the difficulties of gathering historical mortality data. One study found CNS infections to be the leading cause of death, followed by cardiopulmonary arrest. ${ }^{9}$ Another study reported cardiorespiratory and renal causes as the most substantial causes of death. ${ }^{11}$

Since the introduction of prenatal detection, the incidence of myelomeningocele has decreased. ${ }^{3}$ Interestingly, it does not appear to change the mortality rate or the distribution of lesion levels of live-born patients with myelome- ningocele. However, one has to consider the fairly small number of patients born from the year of 2004 forward (n $=23$ ) and, in a mortality analysis perspective, a short-term follow-up of only 12 years.

\section{Data Quality}

Sixteen patients had to be excluded from the study. Fourteen of these patients were born between January 1, 1970 , and December 31,1979 , which is $19 \%$ of all patients born in that decade, accounting for a potential bias. The reason for the missing data is likely to be due to death because registration cannot be found. This could lead to an even higher true mortality rate of this age group.

\section{Conclusions}

This population-based study of patients with myelomeningocele showed increased mortality rates with ascending level of the lesion in the sacral, lumbar, and thoracic regions, respectively. However, this trend does not appear to continue to involve cervical lesions. Furthermore, the mortality rate appears to decrease over time. These findings emphasize that increasing disability expressed as lesion level is a predictor for decreasing survival. Our data also suggest that modern health care development could have an impact on survival for patients with myelomeningocele.

\section{Acknowledgments}

We would like to thank Kåre Schmidt Ettrup, MD, PhD, for revising the manuscript. Joel Haakon Borgstedt-Bakke and Mikkel Mylius Rasmussen received a grant from the Research Foundation concerning congenital malformations connected to Vanførefonden (Forskningsfonden vedrørende medfødte sygdomme under Vanførefonden), and Mikkel Mylius Rasmussen received a grant from the Health Research Fund of Central Denmark Region.

\section{References}

1. Bowman RM, Boshnjaku V, McLone DG: The changing incidence of myelomeningocele and its impact on pediatric neurosurgery: a review from the Children's Memorial Hospital. Childs Nerv Syst 25:801-806, 2009

2. Bowman RM, Mohan A, Ito J, Seibly JM, McLone DG: Tethered cord release: a long-term study in 114 patients. J Neurosurg Pediatr 3:181-187, 2009

3. Clemmensen D, Thygesen M, Rasmussen MM, Fenger-Grøn M, Petersen OB, Mosdal C: Decreased incidence of myelomeningocele at birth: effect of folic acid recommendations or prenatal diagnostics? Childs Nerv Syst 27:1951-1955, 2011

4. Davis BE, Daley CM, Shurtleff DB, Duguay S, Seidel K, Loeser JD, et al: Long-term survival of individuals with myelomeningocele. Pediatr Neurosurg 41:186-191, 2005

5. Dillon CM, Davis BE, Duguay S, Seidel KD, Shurtleff DB: Longevity of patients born with myelomeningocele. Eur J Pediatr Surg 10 (Suppl 1):33-34, 2000

6. Habibi Z, Nejat F, Tajik P, Kazmi SS, Kajbafzadeh AM: Cervical myelomeningocele. Neurosurgery 58:1168-1175, 2006

7. Helweg-Larsen K: The Danish register of causes of death. Scand J Public Health 39 (7 Suppl):26-29, 2011

8. Meyer-Heim AD, Klein A, Boltshauser E: Cervical myelomeningocele-follow-up of five patients. Eur J Paediatr Neurol 7:407-412, 2003

9. Mirzai H, Erşahin Y, Mutluer S, Kayahan A: Outcome of 
patients with meningomyelocele: the Ege University experience. Childs Nerv Syst 14:120-123, 1998

10. MRC Vitamin Study Research Group: Prevention of neural tube defects: results of the Medical Research Council Vitamin Study. Lancet 338:131-137, 1991

11. Oakeshott P, Hunt GM: Long-term outcome in open spina bifida. Br J Gen Pract 53:632-636, 2003

12. Oakeshott P, Hunt GM, Poulton A, Reid F: Expectation of life and unexpected death in open spina bifida: a 40-year complete, non-selective, longitudinal cohort study. Dev Med Child Neurol 52:749-753, 2010

13. Pang D, Dias MS: Cervical myelomeningoceles. Neurosurgery 33:363-373, 1993

14. Roach JW, Short BF, Saltzman HM: Adult consequences of spina bifida: a cohort study. Clin Orthop Relat Res 469:1246-1252, 2011

15. Rocque BG, Bishop ER, Scogin MA, Hopson BD, Arynchyna AA, Boddiford CJ, et al: Assessing health-related quality of life in children with spina bifida. J Neurosurg Pediatr 15:144-149, 2015

16. Steinbok P, Irvine B, Cochrane DD, Irwin BJ: Long-term outcome and complications of children born with meningomyelocele. Childs Nerv Syst 8:92-96, 1992

17. Talwar D, Baldwin MA, Horbatt CI: Epilepsy in children with meningomyelocele. Pediatr Neurol 13:29-32, 1995

18. Vu Minh Arnell M, Seljee Svedberg K, Lindehall B, Jodal U, Abrahamsson K: Adults with myelomeningocele: an interview study about life situation and bladder and bowel management. J Pediatr Urol 9:267-271, 2013
19. Wang JC, Lai CJ, Wong TT, Liang ML, Chen HH, Chan $\mathrm{RC}$, et al: Health-related quality of life in children and adolescents with spinal dysraphism: results from a Taiwanese sample. Childs Nerv Syst 29:1671-1679, 2013

\section{Disclosures}

The authors report no conflict of interest concerning the materials or methods used in this study or the findings specified in this paper.

\section{Author Contributions}

Conception and design: Borgstedt-Bakke, Rasmussen. Acquisition of data: Borgstedt-Bakke. Analysis and interpretation of data: all authors. Drafting the article: Borgstedt-Bakke. Critically revising the article: Fenger-Grøn, Rasmussen. Reviewed submitted version of manuscript: Fenger-Grøn, Rasmussen. Approved the final version of the manuscript on behalf of all authors: BorgstedtBakke. Statistical analysis: all authors. Study supervision: Rasmussen.

\section{Correspondence}

Joel Haakon Borgstedt-Bakke, Department of Neurosurgery, Aarhus University Hospital, Noerrebrogade 44, Bldg. 10, 8000 Aarhus C, Denmark. email: joel.bakke@rm.dk. 